\title{
Comparative study on physicochemical properties of alpha-TCP / calcium sulphate dihydrate biomicroconcretes containing chitosan, sodium alginate or methylcellulose
}

\author{
JOANNA CZECHOWSKA*, ANETA ZIMA, ANNA ŚLÓSARCZYK \\ Faculty of Materials Science and Ceramics, AGH University of Science and Technology, Krakow, Poland.
}

\begin{abstract}
Purpose: Recently, the attention has been drawn to complex systems - biomicroconcretes composed of a bone cement matrix and resorbable granules or microspheres. This paper presents novel bone substitutes composed of $\alpha$-tricalcium phosphate ( $\alpha$-TCP; cement matrix), calcium sulphate dihydrate granules (GCSD; aggregates in biomicroconcrete) and various polymers (chitosan, sodium alginate, methylcellulose) used for the improvement of material properties. The aim of this work was to study $\alpha$-TCP-GCSD-polymer interactions and to compare the impact of organic additives on the physicochemical properties of biomicroconcretes. Methods: Scanning electron microscopy (SEM), mercury intrusion porosimetry (MIP), X-ray diffractometry (XRD) as well as universal testing machine (INSTRON), Gilmore apparatus and $\mathrm{pH} /$ conduct-meter were used. Results: The chemical bonding between $\alpha$-TCP matrix and CSD granules resulted in a compressive strength appropriate for low-load bearing applications (7-12 MPa) and clinically relevant setting times (8-33 min). Biomicroconcretes consisting of sodium alginate possessed the highest mechanical strength $(12 \pm 2 \mathrm{MPa})$. It has also been found that the dissolution-precipitation reactions of the $\alpha$-TCP were retarded with the addition of chitosan and acetic acid. This effect was not observed in the case of methylcellulose and sodium alginate. Chemical stability and bioactivity of materials were demonstrated during in vitro studies in simulated body fluid. Conclusions: Materials containing calcium sulphate-based granules were surgically handy, possessed promising physicochemical properties and are supposed to ensure desired macroporosity as well as gradual resorption in vivo. It has been demonstrated that the presence of CSD granules and polymers influenced the physicochemical properties of composites.
\end{abstract}

Key words: alpha-tricalcium phosphate, calcium sulphate, chitosan, sodium alginate, methylcellulose, biomicroconcrete

\section{Introduction}

Recently, intensive efforts have been undertaken to find new superior biomaterial solutions. Composite materials based on calcium phosphate cements (CPCs) are of great interest due to their excellent biocompatibility and handling properties [18]. CPCs are selfsetting materials with a chemical resemblance to the mineral content of human bone. Many inorganic additives, such as calcium carbonate [22] or calcium sulphate [13], were proposed to obtain calcium phosphate-based biomaterials with desired physicochemical and biological properties. Calcium sulphate (CS) has been used in medicine as a degradable bone filler for many years. Calcium sulphate based bone cements (POP, Plaster of Paris) as well as granules have been developed and applied [8]. The main disadvantage of calcium sulphate is too fast degradation which frequently makes it resorb before the defect is filled by new tissue. On the other hand, CPCs-based systems exhibit poor degradability and generally the process of their resorption occurs layer-by-layer from the outside to the inside [3]. Gradual degradation is beneficial for the regrowth of newly formed bone tissue. Thus, a number of formulations with the controlled degradation rate, containing calcium phosphates and calcium sulphate have been proposed [5], [7]. For example, core-shell calcium sulphate/apatite granules with suppressed in vivo dissolution as well as calcium sulphate/hydroxy-

\footnotetext{
* Corresponding author: Joanna Czechowska, Faculty of Materials Science and Ceramics, AGH University of Science and Technology, al. Mickiewicza 30, 30-059 Kraków, Poland. Phone: +4812 6173952, e-mail: jczech@agh.edu.pl

Received: September 26th, 2019

Accepted for publication: March 3rd, 2020
} 
apatite-based cements were fabricated [26]. Beside inorganic, also biocompatible polymeric additives such as chitosan [27], sodium alginate [6] or gelatine [10], are applied mainly to improve cohesion, handling and mechanical properties of CPCs. When using chitosan, additional advantages such as antibacterial and antifungal properties are also provided. Unfortunately, only a few studies comparing the influence of these additives on physicochemical and biological properties of biomaterials can be found in the literature.

Materials containing bone cements and resorbable granules or microspheres as well as fibres were fabricated [2], [11]. Biphasic CPCs-based materials, consisting of a hardened DCPD (Dicalcium Phosphate Dihydrate, brushite) matrix filled with $\beta$-TCP granules, were developed to optimize CPCs resorption rate [24]. Furthermore, the multiphase composition consisting of CPCs matrix and biphasic calcium phosphate (BCP, $\mathrm{HA}+\beta$-TCP) granules was obtained and examined [12] It has been found that implantation of a biomicroconcrete with $\mathrm{BCP}$ granules promotes the formation of a new bone identical to the host bone. Biodegradable granules can be also applied as delivery vehicles for drugs, growth factors or other biofunctional molecules. Nevertheless, yet, there is no ideal bone cement or biomicroconcrete. Each material must be used based on its merits and with knowledge of its limitations.

In this work, we proposed a new concept - biomicroconcretes based on calcium phosphate matrix and calcium sulphate dihydrate granules (GCSD) as aggregates. According to our knowledge, materials composed of $\alpha$-tricalcium phosphate and GCSD have not been developed and examined yet. We expect that a new bone would be formed in the space left after resorption of the CSD granules, while $\alpha$-TCP cement would act as a guiding matrix. The aim of this work was to study $\alpha$-TCP-CSD-polymer interactions and to compare the impact of various organic additives on the physicochemical properties of biomicroconcretes.

\section{Materials and methods}

\subsection{Materials}

$\alpha$-TCP powder was synthesized by the wet chemical method described elsewhere [4], [15]. In brief, the $\alpha$-TCP powder was sintered above $1250{ }^{\circ} \mathrm{C}(5 \mathrm{~h})$, ground in an attritor mill $(3 \mathrm{~h})$ and sieved below $63 \mu \mathrm{m}$.
$\mathrm{Ca}(\mathrm{OH})_{2}\left(\mathrm{POCH}\right.$, Poland) and $\mathrm{H}_{3} \mathrm{PO}_{4}(\mathrm{POCH}$, Poland $)$ were used as substrates. Calcium sulphate-based granules were prepared by mixing calcium sulphate hemihydrate (CSH, Across Organics, Poland) with distilled water, using liquid-to-powder ratio equal to $0.6 \mathrm{ml} / \mathrm{g}$. Calcium sulphate dihydrate (CSD) was obtained during the setting process, according to Eq. (1).

$$
2 \mathrm{CaSO}_{4} \cdot 0.5 \mathrm{H}_{2} \mathrm{O}+3 \mathrm{H}_{2} \mathrm{O}=2 \mathrm{CaSO}_{4} \cdot 2 \mathrm{H}_{2} \mathrm{O}
$$

Set and hardened material was crushed into the granules $(300-500 \mu \mathrm{m})$. Fabricated granules composed of calcium sulphate dihydrate as the only crystalline phase.

Powder batches were prepared by mixing $\alpha$-TCP powder with CSD granules (GCSD) in a ratio of 1:1. Samples were prepared by mixing powder batches with polymers introduced with the liquid phase. Sodium alginate or methylcellulose in $2.0 \mathrm{wt}$ \% \% solution of $\mathrm{Na}_{2} \mathrm{HPO}_{4}$ as well as chitosan in 0.5 wt. \% solution of acetic acid were applied. Disodium hydrogen phosphate dodecahydrate $\left(\mathrm{Na}_{2} \mathrm{HPO}_{4} \cdot 12 \mathrm{H}_{2} \mathrm{O}\right)$ was purchased from $\mathrm{POCH}$ (Poland). Methylcellulose was received from Sigma-Aldrich (Poland), whereas sodium alginate from Across Organics (Poland). Medium molecular weight chitosan (around 100,000 kDa, DD $\geq 75.0 \%$, viscosity of $200-800 \mathrm{cPs}$ ) from SigmaAldrich was applied. All purchased compounds were analytically pure. Material without organic additive phase was applied as a control. $2.0 \mathrm{wt}$. \%. solution of $\mathrm{Na}_{2} \mathrm{HPO}_{4}$ was used as the liquid phase. Because too low as well as too high liquid to powder ratio reduces the mechanical strength of the final material, the L/P ratio need to be carefully selected and may differ between various liquid phases. In our studies, the lowest possible amounts of liquid phases, which still enables

Table 1. Initial compositions of the developed materials

\begin{tabular}{|c|c|c|c|}
\hline Symbol & Powder phase $(\mathrm{P})$ & Liquid phase (L) & $\begin{array}{l}\mathrm{L} / \mathrm{P} \\
{[\mathrm{g} / \mathrm{g}]}\end{array}$ \\
\hline TS-1 & \multirow{4}{*}{$\begin{array}{l}50 \text { wt. } \% \alpha \text {-TCP } \\
\text { powder: } 50 \text { wt. } \% \\
\text { CSD granules }\end{array}$} & $\begin{array}{l}1.0 \text { wt. } \% \text { solution } \\
\text { of chitosan in } \\
0.5 \text { wt. } \% \text { solution } \\
\text { of acetic acid }\end{array}$ & 0.44 \\
\hline TS-2 & & $\begin{array}{l}1.0 \mathrm{wt} \text { \% } \% \text { solution } \\
\text { of sodium alginate } \\
\text { in } 2.0 \mathrm{wt} . \% \text { solution } \\
\text { of } \mathrm{Na}_{2} \mathrm{HPO}_{4}\end{array}$ & 0.44 \\
\hline TS-3 & & $\begin{array}{l}0.75 \text { wt. \% solution } \\
\text { of methylcellulose } \\
\text { in } 2.0 \text { wt. \% solution } \\
\text { of } \mathrm{Na}_{2} \mathrm{HPO}_{4} \\
\end{array}$ & 0.42 \\
\hline Control & & $\begin{array}{l}2.0 \text { wt. } \% \text { solution } \\
\text { of } \mathrm{Na}_{2} \mathrm{HPO}_{4}\end{array}$ & 0.44 \\
\hline
\end{tabular}


us to obtain consistency suitable for further clinical application of pastes, were used (Table 1).

\subsection{Methods}

\section{Specific surface area}

The specific surface area (SSA) of the initial $\alpha$-TCP and calcium sulphate hemihydrate $(\mathrm{CSH})$ powders was determined by the BET (Brunauer-Emmett -Teller) method using accelerated surface area and porosimetry system ASAP 2010 (Micromeritics).

\section{Phase composition}

The crystalline phases of initial TCP powder and set biomicroconcretes were analyzed via powder X-ray diffraction (D2 Phaser diffractometer, Bruker). The set cements were ground into fine powders and characterized. The phase composition was determined using $\mathrm{CuK}-\alpha$ radiation $(1.54 \AA)$ at $30 \mathrm{kV}$ and $10 \mathrm{~mA}$. The X-rays intensity was recorded in $2 \theta$ range from $10^{\circ}$ to $60^{\circ}$ at $0.02^{\circ}$ intervals and a scanning speed of $1 \% \mathrm{~min}$. The crystalline phases were identified by comparing the experimental diffractograms to the International Centre for Diffraction Data -ICDD: hydroxyapatite (01-074-9778), $\alpha$-TCP (00-009-0348), and calcium sulphate dihydrate (00-036-0432). Rietveld method was applied for phase quantification (Diffrac Suite Topas Rietveld Analysis Software, Bruker). Quality fits were obtained via refining the zero offset, scale factors, and lattice parameters applying a pseudo-Voigt peak shape model. Identification and quantification of the crystalline structures of materials non-incubated and incubated in simulated body fluid - SBF $\left(37^{\circ} \mathrm{C}\right)$ were made after 7 days of setting and hardening. All measurements were done in triplicate and results are presented as mean \pm standard deviation (SD).

Fourier Transform InfraRed Spectroscopy (FTIR) was additionally applied to determine the phase composition of biomaterials. The examined samples were diluted in $\mathrm{KBr}$ and FTIR analysis was carried out in the wavenumber range of $3800-400 \mathrm{~cm}^{-1}$ (Bio-Rad FTS 6000 spectrometer).

\section{Setting times}

The setting times of various cement formulations were identified according to the ASTM C266-08 standard using Gilmore Needles [1]. Results are presented as the average value of six measurements \pm standard deviation (SD).

\section{Microstructure}

The microstructure of fractured samples was observed using the scanning electron microscope (Nova NanoSem 200, JEOL JSM 5400). The chemical compositions in microareas were determined via energy-dispersive X-ray spectroscopy (EDX). Mercury porosimetry was applied to measure open porosity and pore-size distribution of set and hardened biomicroconcretes (AutoPore IV 9500, Micromeritics).

\section{Compressive strength}

The specimens of $6 \mathrm{~mm}$ diameter and $12 \mathrm{~mm}$ high were used for the compressive strength measurements. The specimens were tested at a crosshead speed of $1 \mathrm{~mm} / \mathrm{min}$ using a universal testing machine (Instron 3345).

Statistical analysis was made using one-way ANOVA (ANalysis Of VAriance) with post-hoc Tukey HSD (Honestly Significant Difference) for comparing multiple treatments (the mark $(*)$ means the statistically significant difference between the results, $p>0.01)$.

\section{Chemical stability and bioactivity in vitro}

The chemical stability of materials was evaluated in vitro in simulated body fluid (SBF). Cylindrical samples (12 $\mathrm{mm}$ in diameter and $4 \mathrm{~mm}$ high) were soaked in $40 \mathrm{ml}$ of SBF $\left(37^{\circ} \mathrm{C}\right)$ for 14 days. $\mathrm{pH}$ measurements were done using $\mathrm{pH} /$ conduct-meter Hanna H198129 Combo. All results are presented as mean \pm standard deviation (SD). Bioactivity was evaluated during the incubation of materials in standard SBF according to Kokubo's protocol [14].

\section{Results}

\section{Specific surface area}

The initial $\alpha$-TCP powder possessed the specific surface area equal $5.28 \pm 0.02 \mathrm{~m}^{2} / \mathrm{g}$. SSA of calcium sulphate hemihydrate powder (used to produce granules) was equal to $1.77 \pm 0.04 \mathrm{~m}^{2} / \mathrm{g}$.

\section{Phase composition}

$\mathrm{X}$-ray diffraction analysis of biomicroconcretes revealed that the prepared samples consisted of calcium sulphate dihydrate (45-47 wt. \%) and $\alpha$-TCP (30-37 wt. \%) (Fig. 1). Furthermore, non-stoichiometric hydroxyapatite was present in the amount of 17-24 wt. \% (Table 2). 


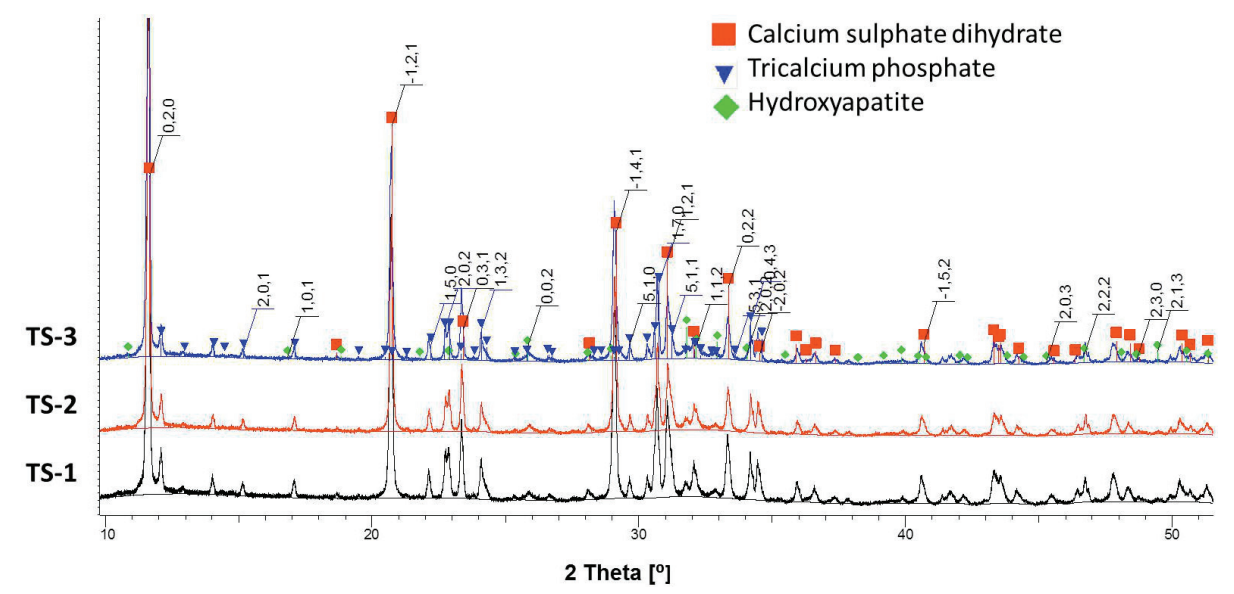

Fig. 1. XRD patterns of set and hardened biomicroconcretes with hkl parameters

Table 2. Phase composition

of set and hardened biomicroconcretes

\begin{tabular}{|l|c|c|c|}
\hline Symbol & $\begin{array}{c}\text { Calcium sulphate } \\
\text { dihydrate [wt. \%] }\end{array}$ & $\begin{array}{c}\alpha \text {-TCP } \\
\text { [wt. \%] }\end{array}$ & $\begin{array}{c}\text { Non-stoichiometric } \\
\text { hydroxyapatite [wt. \%] }\end{array}$ \\
\hline TS-1 & $47 \pm 3$ & $35 \pm 1$ & $18 \pm 3$ \\
\hline TS-2 & $45 \pm 3$ & $34 \pm 1$ & $21 \pm 3$ \\
\hline TS-3 & $46 \pm 3$ & $30 \pm 1$ & $24 \pm 3$ \\
\hline Control & $46 \pm 1$ & $37 \pm 2$ & $17 \pm 3$ \\
\hline
\end{tabular}
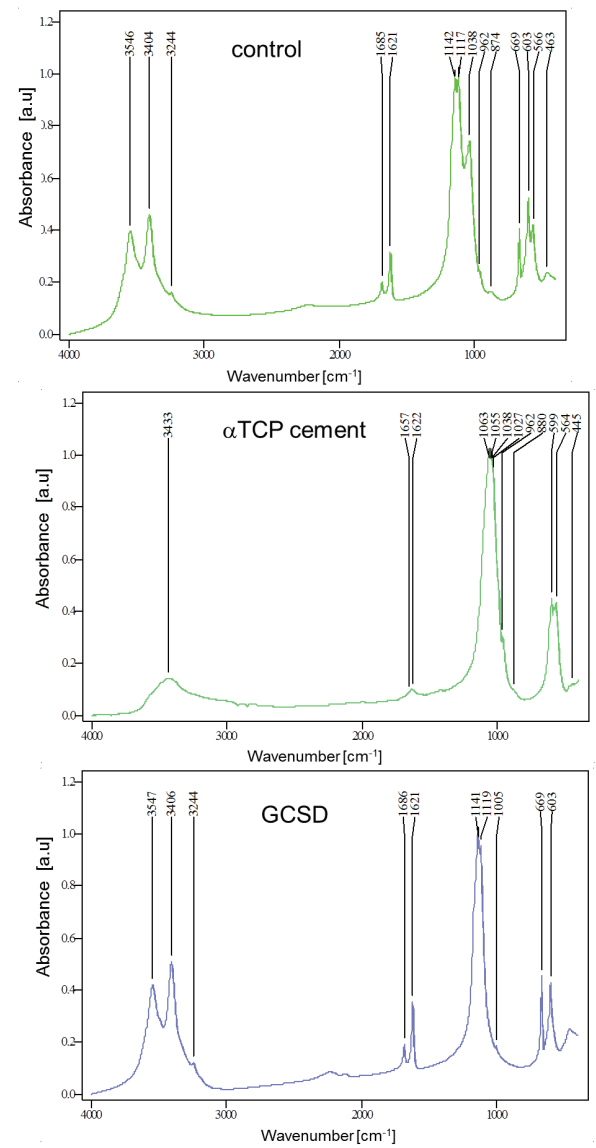

Infrared spectra of biomicroconcretes after setting and hardening revealed the presence of characteristic bands at around 566 and $603 \mathrm{~cm}^{-1}$ that were assigned to triply degenerate $v 4 \mathrm{P}-\mathrm{O}-\mathrm{P}$ bending modes (Fig. 2). The presence of a strong doublet near 602 and 669 $\mathrm{cm}^{-1}$ was connected to $\mathrm{SO}_{4}$ bending vibrations $\left(v_{4}\right)$. The coincidence of $\mathrm{SO}_{4}$ and $\mathrm{PO}_{4}$ bending vibration bands was observed at around $602 \mathrm{~cm}^{-1}$. The strongest
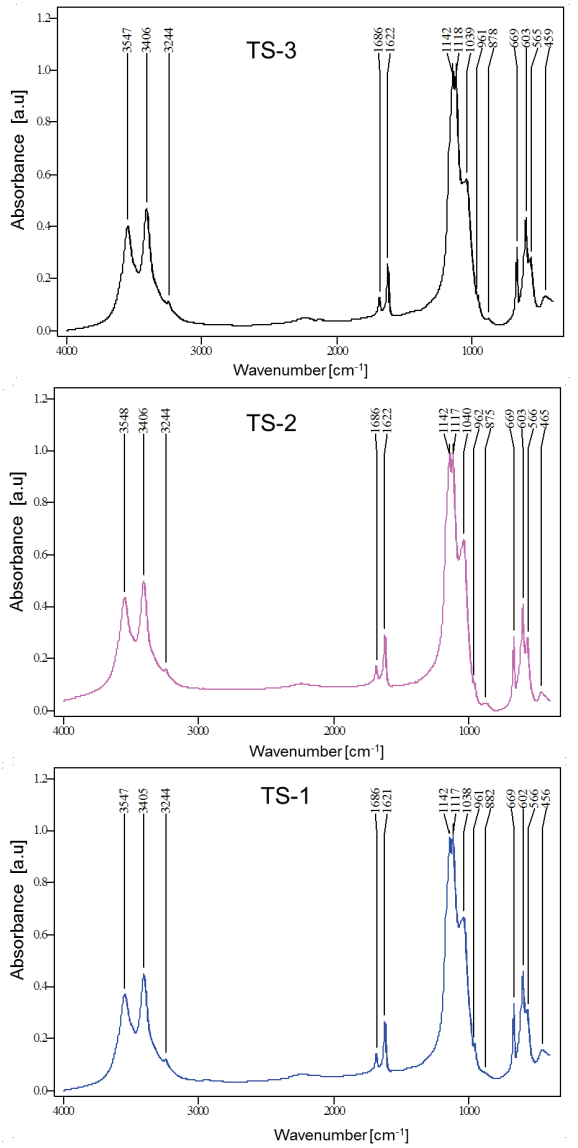

Fig. 2. FT-IR spectra of calcium sulphate granules (GCSD) as well as biomicroconcretes: TS-1, TS-2, TS-3, control and alpha-TCP based cement withouth granules 
bands assigned to calcium phosphates centered at $1062 \mathrm{~cm}^{-1}$ and around $1038-1040 \mathrm{~cm}^{-1}$ were connected with $v_{3}$ anti-symmetric stretching modes of P-O. Band situated at $962 \mathrm{~cm}^{-1}$ came from $v_{1}$ symmetric stretching vibration. Characteristic bands connected with the presence of calcium sulphate dihydrate granules were visible as a doublet near 1045 and $1142 \mathrm{~cm}^{-1}$ (stretching vibrations, $v_{3}$ ). Bands at around $3244 \mathrm{~cm}^{-1}$ $3406 \mathrm{~cm}^{-1}, 3547 \mathrm{~cm}^{-1}$ corresponded to the $-\mathrm{OH}$ stretching modes. Absorption features in the 2080$2400 \mathrm{~cm}^{-1}$ region were assigned to the first order overtones and combinations of the $v_{3}$ absorptions of $\mathrm{SO}_{4}$. Low concentration of polymers in the cements, as well as an overlapping of bands, may explain the lack of visible bands assigned to polymers.

\section{Setting times}

The setting times of materials depended on the liquid phase composition and varied between 8-15 minutes (initial) and 29-44 minutes (final). The setting times of materials TS-2 and TS-3 were similar, whereas in the case of TS-1 (containing chitosan) both initial and final setting times were significantly longer (Table 3 ).

Table 3. Setting times of the materials

\begin{tabular}{|l|c|c|}
\hline \multicolumn{1}{|c|}{ Cement } & Initial $t_{I}[\mathrm{~min}]$ & Final $t_{F}[\mathrm{~min}]$ \\
\hline TS-1 & $15 \pm 1$ & $44 \pm 1$ \\
\hline TS-2 & $8 \pm 1$ & $29 \pm 2$ \\
\hline TS-3 & $8 \pm 1$ & $33 \pm 1$ \\
\hline Control & $8 \pm 1$ & $30 \pm 3$ \\
\hline
\end{tabular}

\section{Microstructure}

Scanning Electron Microscope observations showed microstructure of calcium sulphate granules (Fig. 3d, e) and biomicroconcretes composed of GCSD embedded in a matrix of agglomerated calcium phosphate $(\mathrm{CaP})$ crystals (Fig. 3a-c). The polymeric layer could be observed on the CaPs agglomerates. Calcium sulphate granules consisted of both needle-shaped and plate-like CSD crystals with a high degree of interlocking. Some needle-like calcium sulphate dihydrate crystals could also be visible on the CaPs agglomerates. Mercury porosimetry studies revealed that studied materials had microporous microstructure (Table 4). The set and hardened biomicroconcretes displayed a bimodal pore size distribution and pore diameters ranging from $5 \mathrm{~nm}$ to $2 \mu \mathrm{m}$.

Table 4. Open porosity and pore size distribution in developed materials

\begin{tabular}{|l|c|c|c|}
\hline \multirow{2}{*}{ Material } & \multirow{2}{*}{$\begin{array}{c}\text { Open porosity } \\
{[\text { vol. \%] }}\end{array}$} & \multicolumn{2}{|c|}{ Pore diameter $[\mu \mathrm{m}]$} \\
\cline { 3 - 4 } & $42 \pm 4$ & First range & Second range \\
\hline TS-1 & $42 \pm 3$ & $0.005-0.15$ & $0.15-2.00$ \\
\hline TS-2 & $43 \pm 4$ & $0.008-0.15$ & $0.22-1.50$ \\
\hline TS-3 & $44 \pm 4$ & $0.015-0.17$ & $0.11-1.40$ \\
\hline Control & & \multicolumn{2}{|c}{} \\
\hline
\end{tabular}

\section{Compressive strength}

The results of compressive tests are shown in Fig. 4. The compressive strength of composites ranged from $7 \pm 1 \mathrm{MPa}$ to $12 \pm 2 \mathrm{MPa}$. The highest values were ob-
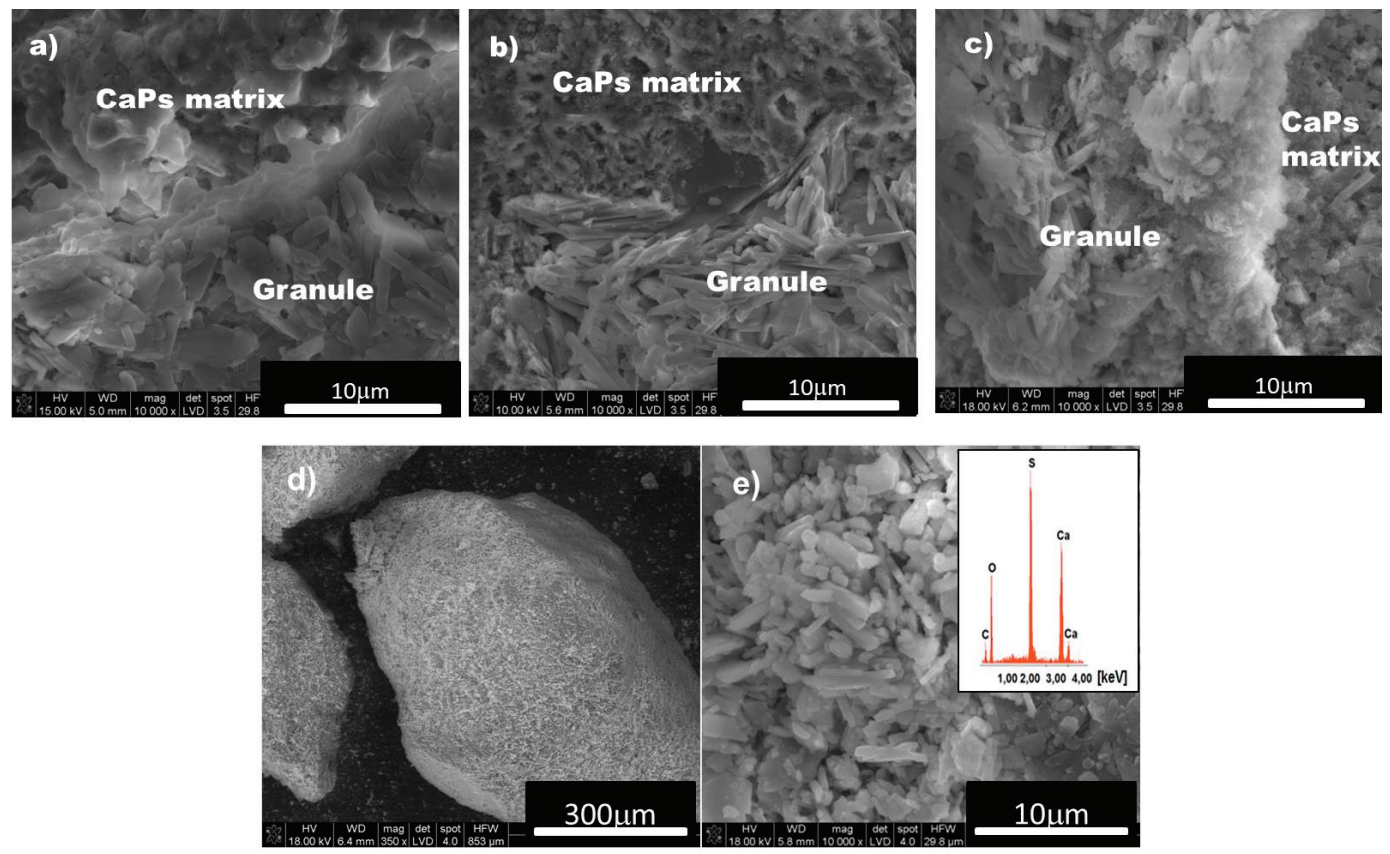

Fig. 3. SEM microphotographs of cross-section of materials:

TS-1(a), TS-2 (b), c) TS-3 (c). SEM microphotographs and EDS analysis of CSD granules (d, e) 
tained for TS-2, where $1.0 \mathrm{wt}$ \% sodium alginate solution in 2.0 wt. $\% \mathrm{Na}_{2} \mathrm{HPO}_{4}$ solution was applied as the liquid phase. Statistically significant difference was observed for TS-1/TS-2, TS-2/TS-3 and TS-2/control $(p>0.01)$.

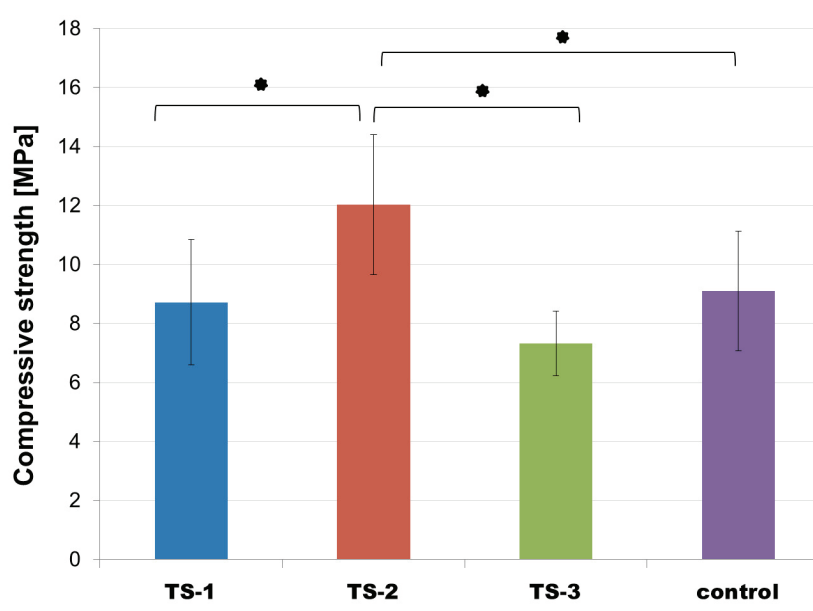

Fig. 4. Compressive strength of biomicroconcretes TS-1, TS-2 and TS-3 after 7 days of setting and hardening $(*$ - statistically significant difference, $p<0.01)$

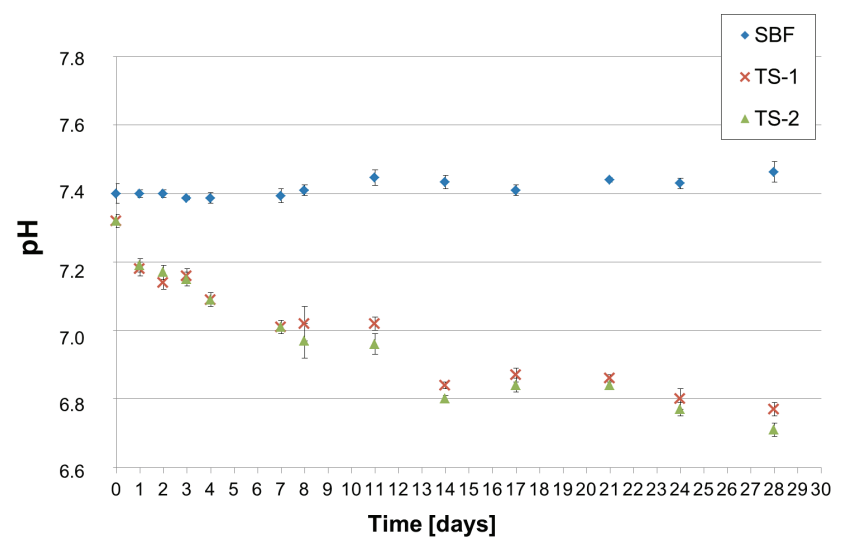

\section{Chemical stability and bioactivity in vitro}

On the basis of obtained results, two materials, namely TS-1 and TS-2, were chosen for further in vitro investigations. Their chemical stability was examined (Fig. 5). During the incubation in simulated body fluid the drop in the $\mathrm{pH}$ value from 7.4 to 6.8 was observed. Furthermore, the increase in the ionic conductivity from 0 to $\sim 2300 \mu \mathrm{S} / \mathrm{cm}$ was recorded. None of the materials disintegrated during testing. The bioactive potential of materials was also estimated via incubation in SBF according to Kokubo's protocol. SEM observations showed that the evenly distributed, thick (TS-1; $7 \mu \mathrm{m}$, TS-2; $10 \mu \mathrm{m}$ ) apatitic layers were created on the materials surfaces' after 7 days of soaking in SBF (Fig. 6).

\section{Discussion}

Biomicroconcretes on the basis of $\alpha$-TCP and calcium sulphate granules (GCSD), modified with poly-

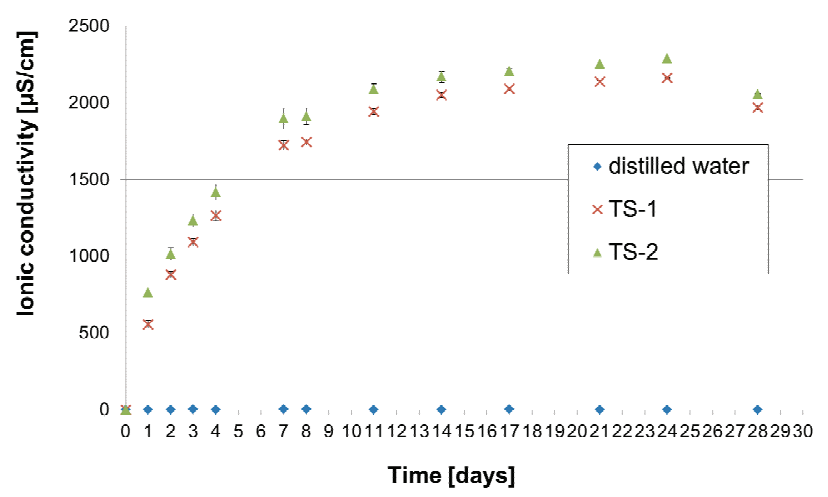

Fig. 5. $\mathrm{pH}$ (a) and ionic conductivity (b) versus time of incubation in simulated body fluid

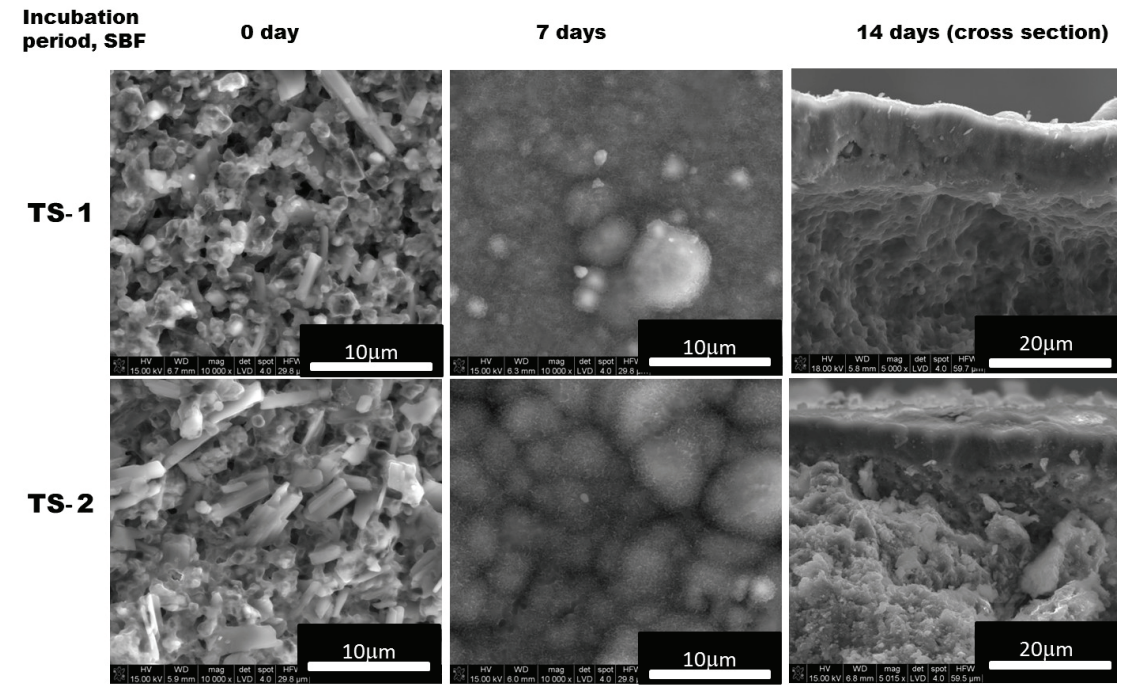

Fig. 6. SEM microphotographs of biomicroconcretes TS-1 and TS-2 after 7 and 14 days of incubation - surfaces and cross sections 
meric additives, were developed. The presence of fast resorbable calcium sulphate dihydrate phase is expected to improve biodegradation rate of $\alpha$-TCP/hydroxyapatite based biomaterials. Furthermore, in vivo resorption of GCSD is supposed to produce macropores and favors bone tissue ingrowth into CPCs matrix.

The FTIR spectra of set materials showed several bands corresponding to sulphate and phosphate groups. XRD analysis revealed that after setting and hardening all biomiconcretes consisted of calcium sulphate dihydrate, $\alpha$-TCP and hydroxyapatite. The initial $\alpha$-TCP powder was monophasic, and thus it can be concluded that non-stoichiometric hydroxyapatite was formed by the hydrolysis of $\alpha$-TCP, according to the Eq. (2)

$3 \alpha-\mathrm{Ca}_{3}\left(\mathrm{PO}_{4}\right)_{2}+\mathrm{H}_{2} \mathrm{O} \rightarrow \mathrm{Ca}_{9}\left(\mathrm{HPO}_{4}\right)\left(\mathrm{PO}_{4}\right)_{5}(\mathrm{OH})$

\section{$\alpha$-TCP non-stoichiometric HA}

There are several factors influencing $\alpha$-TCP setting process, including: (1) presence and the kind of polymer in the liquid phase used for pastes preparation, (2) presence or absence of setting accelerator and (3) chemical reactions on the TCP/GCSD interface. In the case of material TS- 1 chitosan introduced with the liquid phase caused elongation of $\alpha$-TCP setting process. The polymer created a layer around the $\mathrm{CaPs}$ agglomerates, which acted as a barrier and slow down the diffusion of calcium and phosphate ions and thus impede hydrolysis of $\alpha$-TCP into hydroxyapatite. Observed elongation of the setting process stayed in agreement with the results of some earlier studies on CPCs [17], [28], [29]. The similar effect of chitosan layer was observed also for calcium sulphate based bone cements [26], [30]. Furthermore, the retarding effect of organic acid on the dissolution-precipitation reaction of $\alpha$-TCP was also observed in the case of TS-1. Sarada et al. [20] demonstrated that the formation of hydroxyapatite nuclei and their further growing and entanglement in the presence of citric acid is retarded. Ions of organic acids have a strong ability to adsorb onto $\alpha$-TCP particles and give them a highly negative charge, which leads to repulsion between particles and improves flowability [20], [23]. Chitosan can react with acetic acid bonding it and forming an amide linkage. We assume that the resulting amide structures favored the formation of a chitosan layer around $\mathrm{CaPs}$ grains and agglomerates. SEM observations (Fig. 3b, c) revealed that methylcellulose and sodium alginate also created the polymeric layer on the $\mathrm{CaPs}$ agglomerates but in their case, the strong impeding effect on setting process was not observed (Table 3). The main reason for shorter setting times in the case of materials TS-2 and TS-3 was the presence of $\mathrm{Na}_{2} \mathrm{HPO}_{4}$ in the liquid phase composition. $\mathrm{Na}_{2} \mathrm{HPO}_{4}$ is a well-known accelerator of $\alpha$-TCP setting process. $\mathrm{Na}_{2} \mathrm{HPO}_{4}$ introduces additional phosphate ions in the reaction system, shifting the chemical reaction towards the formation of hydroxyapatite. This effect prevails over the impeding effect of polymers. Usually, setting times of single-phase $\alpha$-TCP materials meet the medical requirements and do not exceed 1520 minutes [9] however, there are also works reporting TCP elongated setting up to 29 minutes [21]. In our previous research, we demonstrated that setting times of one-compound, $\alpha$-TCP cements were between 4-7 $\left(t_{I}\right)$ and 9-13 $\left(t_{F}\right)$ [6]. When compared to the results of this study, it can be stated that for more complex systems, such as biomicroconcretes, the additional presence of calcium sulphate granules caused elongation of $\alpha$-TCP setting process. Several approaches may be applied for future improvement of setting times, including: (1) addition of small amount of apatite seeds, (2) reducing $\alpha$-TCP particles size or (3) adding setting accelerators.

The set and hardened biomicroconcretes possessed microporous microstructure formed by calcium sulphate granules embedded in a calcium phosphate matrix. The polymeric layer around the CaPs agglomerates was also visible. Furthermore, needle-like calcium sulphate dihydrate crystals on the CaPs agglomerates were noticed. Their presence was related to the process of GCSD surface dissolution when in contact with the liquid phase and subsequent calcium sulphate dihydrate re-precipitation (Eqs. (3) and (4)).

$$
\mathrm{CaSO}_{4} \cdot 2 \mathrm{H}_{2} \mathrm{O}=\mathrm{Ca}^{2+}+\mathrm{SO}_{4}^{2-}+2 \mathrm{H}_{2} \mathrm{O} \text { (dissolution) }
$$

$\mathrm{Ca}^{2+}+\mathrm{SO}_{4}{ }^{2-}+2 \mathrm{H}_{2} \mathrm{O}=\mathrm{CaSO}_{4} \cdot 2 \mathrm{H}_{2} \mathrm{O}$ (re-precipitation)

These dissolution properties may be modified by the presence of ions which adsorb on the surface and hinder the detachment of $\mathrm{Ca}^{2+}$ and $\mathrm{SO}_{4}^{2-}$ ions. Phosphate and phosphonate salts are known to play this role for calcium salts for both dissolution and growth [16], [19]. This kind of reaction with phosphate ions was also observed in the case of developed biomicroconcretes.

The pore size distribution of biomicroconcretes has two clear maxima - the first peak $(\sim 5 \mathrm{~nm}-0.15 \mu \mathrm{m})$ was connected to pores inside granules, whereas the second peak $(\sim 0.15 \mu \mathrm{m}-2 \mu \mathrm{m})$ was assigned to pores between calcium phosphate agglomerates in the matrix (Table 4). It is expected that in vivo designed biomicro- 
concretes will gain macroporosity due to the preferential dissolution of the CSD granules compared to calcium phosphates in the matrix ( $\alpha$-TCP, CDHA). Further investigations are necessary to confirm this hypothesis.

In order to examine the influence of (1) organic component and (2) CSD granules on mechanical properties of materials, the compressive strength of the obtained materials was tested (Fig. 4). The compressive strength of composites ranged from $7 \pm 1 \mathrm{MPa}$ to $12 \pm 2 \mathrm{MPa}$ and the highest values were obtained for TS-2, where $1.0 \mathrm{wt}$. \% sodium alginate solution in 2.0 wt. $\% \mathrm{Na}_{2} \mathrm{HPO}_{4}$ solution was applied. Obtained results stayed in agreement with our previous studies, which showed that the presence of sodium alginate has a positive impact on the mechanical strength of $\alpha$-TCP based formulations [6]. One-component $\alpha$-TCP cements containing sodium alginate $(20 \pm 8 \mathrm{MPa})$ possessed higher mechanical strength than those with methylcellulose $(17 \pm 4 \mathrm{MPa})$ and without polymer $(14 \pm 3 \mathrm{MPa})[6]$. In the case of examined $\alpha$-TCP/GCSD biomicroconcretes, the compressive strength values were about twice as low. An exception is material TS-1, containing chitosan. In our previous study [4] we reported that the compressive strength of $\alpha$-TCP/chitosan cement was equal to $8 \pm 3 \mathrm{MPa}$, which is similar to value obtained now for composite $\alpha$-TCP/GCSD/chitosan (TS-1; $9 \pm 2 \mathrm{MPa}$ ). However, as a rule of thumb, the presence of granules decreased the compressive strength of materials. This may be explained by the observation that mechanical properties of materials are obtained through the chemical and physical entanglement of crystals. This entanglement results from the chemical reactions involving dissolution of reactants, nucleation and precipitation of new crystals. So, the highest possible compressive strength values are usually obtained for single component CPCs. It can be concluded that the compressive strength of materials is provideed mainly by $\alpha$-TCP matrix. Still, it can be said that chemical bonding between TCP matrix and CSD granules resulted in a relatively high mechanical strength. Calcium sulphate and $\alpha$-tricalcium phosphate react with each other to create non-stoichiometric hydroxyapatite. Dissolution of $\mathrm{CaSO}_{4} \cdot 2 \mathrm{H}_{2} \mathrm{O}$ on the $\alpha$-TCP/GCSD interface can lead to a partial substitution of phosphate groups $\left(\mathrm{HPO}_{4}\right)$ in the non-stoichiometric hydroxyapatite structure $\left(\mathrm{Ca}_{9}\left(\mathrm{HPO}_{4}\right)_{2}\left(\mathrm{PO}_{4}\right)_{4}(\mathrm{OH})_{2}\right)$ via $\mathrm{SO}_{4}^{2-}$. The ionic radius of $\mathrm{PO}_{4}^{3-}$ ions vary from those of $\mathrm{SO}_{4}^{2-}$, whereas the ionic radius of $\mathrm{HPO}_{4}^{2-}$ closely matches it $\left(\mathrm{HPO}_{4}^{2-}, 0.236 \mathrm{~nm} ; \mathrm{SO}_{4}^{2-}, 0.230 \mathrm{~nm}\right)$ [25]. Therefore, it may be assumed that hydroxyapatite was formed by the substitution of $\mathrm{SO}_{4}^{2-}$ by $\mathrm{HPO}_{4}^{2-}$ ions in the hydroxyapatite structure. The reaction can be as follows:

$$
\begin{gathered}
9 \mathrm{CaSO}_{4} \cdot 2 \mathrm{H}_{2} \mathrm{O}+6 \mathrm{HPO}_{4}^{2-} \\
=\mathrm{Ca}_{9}\left(\mathrm{SO}_{4}\right)_{2}\left(\mathrm{PO}_{4}\right)_{4}(\mathrm{OH})_{2}+6 \mathrm{H}^{+}+7 \mathrm{SO}_{4}^{2-} \\
+2 \mathrm{HPO}_{4}^{2-}+16 \mathrm{H}_{2} \mathrm{O}
\end{gathered}
$$

$\mathrm{XRD}$ analysis confirmed changes in the structure of $\mathrm{SO}_{4}^{2-}$ substituted hydroxyapatite in comparison to hydroxyapatite formed in the absence of calcium sulphate ions. The lattice parameters of $\mathrm{SO}_{4}^{2-}$ substituted hydroxyapatite were equal $a=b=9.402 \AA, c=6.880 \AA$ $\left(V=527 \AA^{3}\right)$, whereas for undoped-hydroxyapatite $a=b=9.440 \AA, c=6.877 \AA\left(V=531 \AA^{3}\right)$. Furthermore, the FT-IR analysis revealed that bands corresponding to anti-symmetric stretching $\left(v_{3} ; 1038-1040\right.$ $\left.\mathrm{cm}^{-1}\right)$ and bending modes $\left(v_{4} ; 566\right.$ and $\left.603 \mathrm{~cm}^{-1}\right)$ of $\mathrm{P}-\mathrm{O}$ were slightly shifted toward higher wavenumber in comparison to $\alpha$-TCP based cement without GCSD granules $\left(1038 \mathrm{~cm}^{-1}, 564 \mathrm{~cm}^{-1}, 599 \mathrm{~cm}^{-1}\right)$ and bands described in the literature (i.e., $1034 \mathrm{~cm}^{-1}, 563 \mathrm{~cm}^{-1}$ and $600 \mathrm{~cm}^{-1}$ [4]).

On the basis of obtained results, two materials (TS-1 and TS-2) were chosen for further in vitro investigations. The decrease in the $\mathrm{pH}$ value from 7.4 to 6.8 and the increase in the ionic conductivity from 0 to $\sim 2300 \mu \mathrm{S} / \mathrm{cm}$ in the case of TS-1 and TS-2 materials may indicate a gradual dissolution of sulphate granules during incubation in SBF and distilled water solutions, respectively (Fig. 5). The bioactive potential of materials was also estimated via incubation in simulated body fluid. It has been found that the presence of calcium sulphate granules favors creation of thick (TS-1; $7 \mu \mathrm{m}, \mathrm{TS}-2 ; 10 \mu \mathrm{m}$ ), evenly distributed apatitic layer in simulated body fluid (Fig. 6). Calcium sulfate dihydrate is an easily soluble compound that releases a large amount of calcium ions into the reaction system. Those ions can react with the phosphate ions present in SBF to form hydroxyapatite according to Eqs. (5) and (6):

$$
\begin{gathered}
9 \mathrm{CaSO}_{4} \cdot 2 \mathrm{H}_{2} \mathrm{O}+6 \mathrm{HPO}_{4}^{2-} \\
=\mathrm{Ca}_{9}\left(\mathrm{HPO}_{4}\right)_{2}\left(\mathrm{PO}_{4}\right)_{4}(\mathrm{OH})_{2}+6 \mathrm{H}^{+} \\
+9 \mathrm{SO}_{4}^{2-}+16 \mathrm{H}_{2} \mathrm{O}
\end{gathered}
$$

Changes in the local supersaturation of simulated body fluid towards the precipitation of apatite promote the formation of heterogeneous apatite seed crystals and thus accelerate the formation of the apatite layer on the surface of the samples. 


\section{Conclusions}

In this study, biomicroconcretes on the basis of $\alpha$-TCP (cement matrix) and calcium sulphate granules (GCSD, aggregates) modified with polymeric additives were developed and examined. It has been demonstrated that both calcium sulphate granules and polymers influenced the physicochemical properties of composites. Calcium sulphate granules caused elongation of $\alpha$-TCP setting process. This is particularly evident for biomicroconcrete containing chitosan and acetic acid. It has been found that chitosan created a layer around the CaPs agglomerates, which acted as a diffusion barrier for water, $\mathrm{Ca}^{2+}$ and $\mathrm{PO}_{4}^{3-}$ ions. The retardation effect was not observed in the case of methylcellulose and sodium alginate, probably due to the presence of setting process accelerator $-\mathrm{Na}_{2} \mathrm{HPO}_{4}$. It has been shown that biomaterials containing GCSD displayed a bimodal pore size distribution and pore diameters ranging from $5 \mathrm{~nm}$ to $2 \mu \mathrm{m}$. It has been found that granules lower mechanical strength of $\alpha$-TCP-based biomaterials. Nevertheless, the compressive strength values (7-12 MPa) suitable for low bearing places applications were obtained. Good mechanical properties can be connected to $\alpha$-TCP matrix as well as the chemical bonding between $\alpha$-TCP matrix and GCSD. Formation of sulphate-substituted hydroxyapatite $\mathrm{Ca}_{9}\left(\mathrm{SO}_{4}\right)_{2}\left(\mathrm{PO}_{4}\right)_{4}(\mathrm{OH})_{2}$ ensured strong interconnection between components on the granule/matrix interface. The influence of polymer type on mechanical properties was also visible. The highest compressive strength was obtained for material containing sodium alginate $(12 \pm 2 \mathrm{MPa})$. In vitro studies revealed that developed biomaterials were chemically stable and supported the formation of thick and evenly distributed apatitic layer on their surfaces during incubation in SBF. Thus, the materials can be considered as potentially bioactive. We believe that resorption of CSD would, additionally favor bone ingrowth into CPCs matrix and a new bone tissue will be formed in the macropores left after resorption of GCSD. Further research is necessary to confirm this hypothesis.

\section{Acknowledgements}

The work was supported by the Polish National Science Center - project No. 2017/27/B/ST8/01173.

\section{Data availability}

The raw/processed data required to reproduce these findings cannot be shared at this time due to technical or time limitations.

\section{References}

[1] ASTM C266-18, Standard test method for time setting of hydraulic-cement paste by gillmore needles, ASTM Annual Book of Standards, American Society for Testing and Materials, West Conshohocken, PA, 04.01, 19428-2959.

[2] Boenm A., Meininger S., Tesch A., Gbureck U., Müller F., The Mechanical Properties of Biocompatible Apatite Bone Cement Reinforced with Chemically Activated Carbon Fibers, Materials, 2018, 11 (2), 192.

[3] Bohner M., Calcium orthophosphates in medicine: from ceramics to calcium phosphate cements, Injury, 2000, 31, D37-D47.

[4] Czechowska J., Zima A., Paszkiewicz Z., Lis J., ŚLÓSARCZYK A., Physicochemical properties and biomimetic behaviour of $\alpha$-TCP-chitosan based materials, Ceram. Int., 2014, 40 (4), 5523-5532.

[5] Czechowska J., Zima A., Siek D., ŚlósarczyK A., The importance of chitosan and nano-TiHA in cement-type composites on the basis of calcium sulfate, Ceram. Int., 2016, 42 (14), 15559-15567.

[6] Czechowska J., Zima A., Siek D., Ślósarczyk A., Influence of sodium alginate and methylcellulose on hydrolysis and physicochemical properties of $\alpha$-TCP-based materials, Ceram. Int., 2018, 44(6), 6533-6540.

[7] Demir Ö., Ege D., Rheological and Mechanical Properties of Thermoresponsive Methylcellulose/Calcium Phosphate-Based Injectable Bone Substitutes, Materials, 2018, 11 (4), 604.

[8] FERrando A., PART J., BAEZA J., Treatment of cavitary bone defects in chronic osteomyelitis: bioactive glass S53P4 vs. calcium sulphate antibiotic beads, J. Bone Jt. Infect., 2017, 2 (4), 194-201.

[9] Ginebra M.P., Fernández E., Driessens F., Planell J.A., Modeling of the Hydrolysis of $\alpha$-Tricalcium Phosphate, J. Am. Ceram. Soc., 1999, 82(10), 2808-2812.

[10] Habraken W.J., Wolke J.G., Mikos A.G., Jansen J.A., Porcine gelatin microsphere/calcium phosphate cement composites: an in vitro degradation study, J. Biomed. Mater. Res. B, 2009, 91 (2), 555-561.

[11] Hu M., He Z., Han F., Shi C., Zhou P., Ling F., Zhu X., YANG H., LI B., Reinforcement of calcium phosphate cement using alkaline-treated silk fibroin, Int. J. Nanomed, 2018, 13, 7183.

[12] Julien M., Khairoun I., Legeros R.Z., Delplace S., Pilet P., Weiss P., Daculsi G., Bouler J.M., Guicheux J., Physico-chemical-mechanical and in vitro biological properties of calcium phosphate cements with doped amorphous calcium phosphates, Biomaterials, 2007, 28 (6), 956-965.

[13] Kasioptas A., SAndell V., Lidén E., BöRJesson O., NILSSON M., Characterization and monitoring of the evolution of a calcium phosphate/calcium sulfate self-setting bone cement, Key Eng. Mater., 2012, 153-158.

[14] Kokubo T., Takadama H., How useful is SBF in predicting in vivo bone bioactivity?, Biomaterials, 2006, 27 (15), 2907-2915.

[15] Kolmas J., KaflaK A., Zima A., ŚlósarczyK A., Alphatricalcium phosphate synthesized by two different routes: Structural and spectroscopic characterization, Ceram. Int., 2015, 41 (4), 5727-5733.

[16] LiU S.T., NANCOLLAS G.H, The crystal growth of calcium sulfate dihydrate in the presence of additives, J. Colloid Interface Sci., 1973, 44 (3), 422-429.

[17] Medvecky L., Stulajterova R., Giretova M., Faberova M. Properties of Powder Composite Polyhydroxybutyrate-Chitosan- 
-Calcium Phosphate System, Powder Metall. Prog., 2017, 17 (1), 1-9.

[18] Olkowski R., Kaszczewski P., Czechowska J., Siek D., Pijocha D., Zima A., ŚlósarczyK A., LewandowsKa-SzUMIEt M., Cytocompatibility of the selected calcium phosphate based bone cements: comparative study in human cell culture, J. Mater. Sci.: Mater. Med., 2015, 26 (12), 270.

[19] Pachon-Rodriguez E.A., Colombani J., Pure dissolution kinetics of anhydrite and gypsum in inhibiting aqueous salt solutions, AIChE. J., 2013, 59 (5), 1622-1626.

[20] Sarda S., Fernandez E., Nilsson M., Balcells M., Planell J.A., Kinetic study of citric acid influence on calcium phosphate bone cements as water-reducing agent, J. Biomed. Mater. Res., 2002, 61 (4), 653-659.

[21] Shahrezaei M., Shahrouzi J., Hesaraki S., Zamanian A., The Effect of $\alpha$-TCP Particle Size on Mechanical and Setting Properties of Calcium Phosphate Bone Cements, J. Arch. Mil. 2014, 2 (2), 16516.

[22] Siek D., Ślósarczyk A., Przekora A., Belcarz A., Zima A., GinalsKa G., CZEChOWsKa J., Evaluation of antibacterial activity and cytocompatibility of $\alpha-T C P$ based bone cements with silver-doped hydroxyapatite and $\mathrm{CaCO}_{3}$, Ceram. Int., 2017, 43 (16), 13997-14007.

[23] Tenhuisen K.S., Brown P.W., The effects of citric and acetic acids on the formation of calcium-deficient hydroxyapatite at 38 C, J. Mater Sci.: Mater Med., 1994, 5 (5), 291-298.

[24] Theiss F., Apelt D., Brand B., Kutter A., Zlinszky K., Bohner M., Matter S., Frei C., Auer J.A., Von
RECHENBERG B., Biocompatibility and resorption of a brushite calcium phosphate cement, Biomaterials, 2005, 26 (21), 4383-4394.

[25] Toyama T., Kameda S., Nishimiya N., Synthesis of Sulfateion-substituted Hydroxyapatite from Amorphous Calcium Phosphate, Bioceram. Dev. Appl., 2013, S1: 011, DOI: 10.4172/2090-5025.S1-011.

[26] Tsuchiya A., Sato M., TAKahashi I., Ishikawa K., Fabrication of apatite-coated gypsum granules and histological evaluation using rabbits, Ceram. Int., 2018, 44(16), 2033020336.

[27] XU H.H., Simon Jr C.G., Fast setting calcium phosphatechitosan scaffold: mechanical properties and biocompatibility, Biomaterials, 2005, 26(12), 1337-1348.

[28] Zhang J., Liu W., Schnitzler V., TANCRet F., Bouler J.M., Calcium phosphate cements for bone substitution: chemistry, handling and mechanical properties, Acta Biomater., 2014, 10 (3), 1035-1049.

[29] Zima A., Czechowska J., Siek D., Olkowski R., Noga M., LewandowsKa-SzUmiet M., ŚlÓSARCZyK A., How calcite and modified hydroxyapatite influence physicochemical properties and cytocompatibility of alpha-TCP based bone cements, J. Mater. Sci.: Mater. Med., 2017, 28 (8), 117.

[30] Zima A., Czechowska J., Siek D., Ślósarczyk A., Influence of magnesium and silver ions on rheological properties of hydroxyapatite/chitosan/calcium sulphate based bone cements, Ceram. Int., 2017, 43 (18), 16196-16203. 